\title{
Evaluation of Coating Systems for Steel Aluminum Hybrid Casting
}

\author{
Xiangfan Fang \\ Institute of Automotive Lightweight Design, University of Siegen, Siegen 57076, Germany
}

\begin{abstract}
Hybrid casting is a well known technology to join steel inserts and Aluminum. State of the art is to produce force and form locked connections, since the material based connection is very brittle. In the current work, a new metal coating concept has been developed based on the recent development of intermetallic alloys and surface coatings for Fe-Al-X-system. The new PVD coating consists of two sub-layers. The first layer is less than $3 \mu \mathrm{m}$ in thickness and consists of $\mathrm{Fe}$, Si as well as lower Al-content. A second layer consists of only $\mathrm{Al}$ and $\mathrm{Si}$. For developed process parameters of die casting and Al-alloy, a reproducible material based connection with more than $10 \mathrm{MPa}$ shear tensile stress and ductile behavior could be produced. Based on SEM (Scanning electron microscopy)study on coating layer morphology and composition as well as fracture surface, the mechanisms for the new material joining have been investigated. The special chemical composition, the thicknesses of the new coating layer in combination with the casting conditions are found to be responsible for the ductile behavior of the joining between steel and Aluminum. For the first time, there is a chance to apply steel Aluminum hybrid casting technique on real products.
\end{abstract}

Key words: Hybrid casting, Fe-Al-intermetallic phase, interfacial diffusion reaction, coating systems, die casting process, material based joining, ductile fracture.

\section{Introduction}

In the last few years, with the increasing requirement on light weight design and cost saving, considerable attention has been paid to multi-material design in automotive body and chassis structures. It means that the right material should be used for the right applications in order to achieve the best compromise between weight and cost in the final product.

Beside of this, the modern vehicle BIW (body in white) is being built by using platform. In this case, several different types of BIWs must be built on the same assemble line. For example, all steel or steel intensive BIW are selected for the conventional vehicle because of the lower requirement on weight saving. On the other hand, due to the tremendous demands of weight reduction for the full electric vehicle, steel-Aluminum hybrid designs or Aluminum intensive designs can be selected to obtain more

Corresponding author: Xiangfan FANG, professor, research field: automotive light weight design. driving range and reduce the expanses of battery systems. In order to join the steel and the Aluminum parts, many different new joining technologies such as riveting and adhesive bonding have been developed, which requires expensive investments in assemble lines and thus hinders the use of multi-material systems.

Therefore the author proposed a new method to be able to build both steel intensive design BIW and steel-aluminum mix-material design BIW with the same assemble line. For this kind of flexible BIW structure, a type of modular platform using hybrid casting gussets could be a good choice. In this hybrid casing method, the steel parts (red) are small inserts, as illustrated in Fig. 1, which are molded during the Al-casting (white) process. Here, the gussets for upper and lower A-pillar are designed in Aluminum-casting and the parts in between, i.e. A-pillar reinforcement can be made of both steel or Aluminum. It is easy to imagine that further gussets could be used in the other areas as well. For a steel intensive BIW, only the gussets 


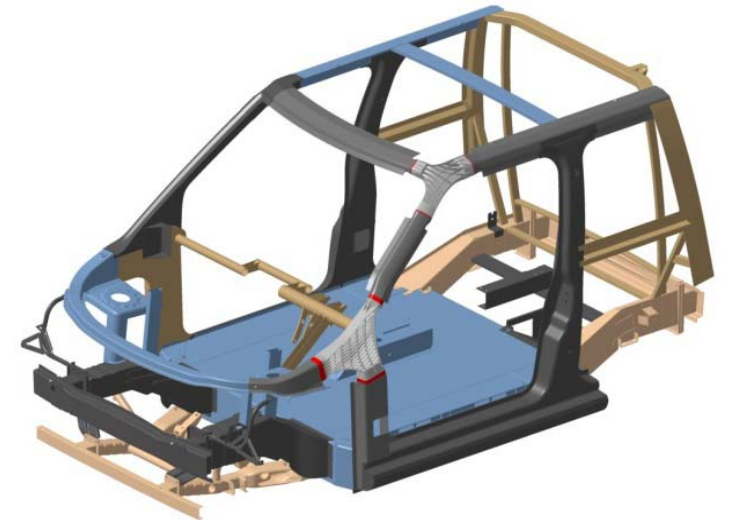

Fig. 1 Hybrid gussets Al-Steel for a full electric urban utility vehicle (red parts: steel inserts, white parts: Al-casting nodes).

are made of Aluminum and for the light weight full electric vehicles all the parts in between can be designed in Aluminum as well.

\section{State of the Art}

\subsection{Hybrid Casting and Al-Steel Joining}

Hybrid casting is a well known technique to join steel and Aluminum during Al-casting. All processes up to now use only the following two mechanisms, the form locking and the force locking or force based connection. In Refs. [1, 2], a compression force between Aluminum and steel core parts was generated when Aluminum melt cools down to room temperature during the hybrid casting process, i.e. Al-shrinkage was used to join steel insert parts with Al-Casting around them, which was proposed in Ref. [3] as well. The steel parts must have cylinder shape. Holes have been designed into steel parts, where Al-cast can flow in and build both form locking and force locking connections. Roeth [4] proposed the same type of connection, where Al-casting in the inner area of a steel part should reinforce this sheet steel deep drawing part. Because steel and Aluminum cannot be welded together, no efficient ductile material based connection could be realized up to now $[5,6]$. This is because during the welding process, very brittle $\mathrm{Al}-\mathrm{Fe}$ intermetallic compounds or IMP (intermetallic phase) can be formed. However, since the form locking and the force based connection are not strong enough to resist the high level static and especially the dynamical loads during a vehicle usage, such kind of connections could not be used in the real vehicle production successfully.

The target of the current investigation is therefore to develop a material based joining between steel and Aluminum. Although steel and Aluminum cannot be welded together, they can still form different types of IMPs. So, the goal of this research work was to develop a surface coating, with which a ductile IMP can be formed when the coated steel is casted with Aluminum alloys. In the following, the state of art of welding and inter-diffusion between steel and Aluminum should be described.

\subsection{Influence of Different Elements of the Formation of IMP}

According to Refs. [7-9], different alloy elements such as $\mathrm{B}, \mathrm{Zr}$ and Mo may increase the ductility of FeAl-type IMP. Jacome et al. [5] used different filler materials, such as A199.5, AlMn1, AlSi5 and AlSi3Mn1, to improve the welding results between a $\mathrm{Zn}$ coated steel (14 $\mu \mathrm{m} \mathrm{Zn} \mathrm{Layer)} \mathrm{and} \mathrm{Al} 5182$ materials $(0.2 \% \mathrm{Si}, 0.5 \% \mathrm{Mn}$ and $5 \% \mathrm{Mg})$ through a low heat input method which is called CMT (cold metal transfer) welding. By using the different filler materials, different IMPs from steel to Aluminum in the order of $\alpha-\mathrm{Fe}, \eta-\mathrm{Al}_{5} \mathrm{Fe}_{2}, \theta-\mathrm{Al}_{3} \mathrm{Fe}, \alpha-\mathrm{Al}$ or $\alpha-\mathrm{Fe}, \eta-\mathrm{Al}_{5} \mathrm{Fe}_{2}, \theta-\mathrm{Al}_{3} \mathrm{Fe}, \alpha_{\mathrm{c}}-\mathrm{AlFeSi}$, $\alpha-\mathrm{Al}$ could be detected, which corresponds to different failure modes during tensile tests. When using AlSi3Mn1 type of filler material, the joining failed in base material which is the best case. While for AlSi5, the failure occurred across the weld seams in Al-side. And for both AlSi3Mn1 and AlSi5 type of filler materials, the amount of IMP $\alpha_{c}-\mathrm{AlFeSi}$ increases and the total thickness of the IMP decreases. This ordered $\alpha$ type crystal structure is cubic and may have many dislocation sliding systems. Thus it is more ductile than the other types of crystal structures such 
as orthorhombic for $\eta-\mathrm{Al}_{5} \mathrm{Fe}_{2}$, or monoclinic for $\theta-\mathrm{Al}_{3} \mathrm{Fe}$ [10], where very few or even no sliding systems for dislocations gliding are available.

In Ref. [10], Springer et al. investigated the formation and growth of intermetallic phases during inter-diffusion between low carbon steels and Aluminum alloys in order to determine the influence of $\mathrm{Si}$ as an alloying element in Aluminum alloys. Both 99.99 wt.\% pure Aluminum and Al-5 wt.\% Si alloys were studied together with a commercial low-carbon steel. The authors set diffusion conditions for solid-solid, solid-semi-solid and solid-liquid diffusion at $600{ }^{\circ} \mathrm{C}$ and $675{ }^{\circ} \mathrm{C}$, respectively. In the case of solid/semi-solid to solid diffusion, bare steel was used. For liquid to solid diffusion, a $\mathrm{Zn}$ dip coated steel with $140 \mathrm{~g} / \mathrm{m}^{2} \mathrm{Zn}$ layer was used, which corresponds to a $20 \mu \mathrm{m}$ thick $\mathrm{Zn}$ layer. This kind of coating was known to be often used in hybrid casting process as well $[3,4,11]$. During the experiments, it was found that the total thickness of the intermetallic layer is mainly governed by the growth of the Al-rich $\eta-\mathrm{Al}_{5} \mathrm{Fe}_{2}$, which has an orthorombic crystal structure with low symmetry and thus is brittle.

Furthermore, the addition of Si to Aluminum has different effects for different diffusion conditions. When steel is put into a melting Aluminum pot, $\mathrm{Si}$ decelerates the growth of the IMP layer. However, it accelerates the growth of the IMP under solid to semi-solid inter-diffusion conditions. Applied to hybrid casting, this means that $\mathrm{Si}$ in Al-alloy reduces the thickness of the brittle layer of $\eta-\mathrm{Al}_{5} \mathrm{Fe}_{2}$, which improves the properties of the joint consisting FeAl-intermetallics. Si has already been added in most of the Al-cast-alloys. So, the positive effect of Si has been there already. In Ref. [12] it was found that voids may be formed during the inter diffusion due to Kirkendall effect.

No matter what kind of alloys and temperatures were used, the formation of the IMP is controlled by their kinetics [13-15]. The brittle IMP with high Aluminum content was formed at first and very fast
[14], before the other IMPs according to the Thermodynamics [15] could be formed. However, all tests were done by using un-coated bare steel or Zn-coated sheet metal, because of the positive effects of $\mathrm{Zn}$-coating although the physical background of the effect of the Zn-coating has been so far not understood sufficiently. One explanation is that the steel surface can be isolated from the oxidation through $\mathrm{Zn}$-coating, which improves the joining possibilities to $\mathrm{Al}$. Oberschelp [11] stated that $\mathrm{Zn}$ can be solved by 83.1 wt. $\%$ in Al-melt at a temperature of $381^{\circ} \mathrm{C}$. A kind of material based connection could be created by this kind of material mixture. There were no deep investigations on coatings other than $\mathrm{Zn}$, which may change or at least influence the phase building kinematics of FeAl IMPs. This aspect will be investigated in the current work, such as Al-Si coating below.

\subsection{The Evolution of IMPs in an Al-Si-layer during} Heat Treatment

The IMP evolution in an industrial hot dip coated Al-Si steel was investigated in Refs. [16-18]. The kinematics of the IMPs in such kind of coatings seems to be different from the findings Ref. [10]. In Ref. [17], the behavior of low carbon boron steel, which was hot dip coated by an Al-Si coating layer with 20 $\mu \mathrm{m}$ initial thickness and $10 \mathrm{wt} . \% \mathrm{Si}$, was analyzed. It was heat treated at $950{ }^{\circ} \mathrm{C}$ for different time. After a short time of $30 \mathrm{~s}, 5$ different IMPs were detected by SEM (scanning electron microscopy) and the calculated ternary phase diagram: starting from the surface of the coating layer a $\eta-\mathrm{Al}_{5} \mathrm{Fe}_{2}$ phase, followed by an ordered $\mathrm{BCC}$ phase, then the $\mathrm{Al}_{2} \mathrm{Fe}$, an ordered $\mathrm{BCC}$ phase and a disordered $\mathrm{BCC}$ phase, have been identified. The Al-content in the layer decreases from $50 \%$ at surface to a minimum of about $30 \%$ at the depth of $3 \mu \mathrm{m}$. After that point, it increases again to $50 \%$ at the depth of $7 \mu \mathrm{m}$ and decreases to zero on the border of steel substrate. When the same steel is heat treated at $950{ }^{\circ} \mathrm{C}$ for $5 \mathrm{~min}$, only two 
IMPs could be determined, which is an ordered and a disordered BCC phase.

Based on Ref. [18], Jenner et al. [18] outlined that the growth of an Al-coating layer without $\mathrm{Si}$ is much faster than that with $\mathrm{Si}$. Si would occupy the vacancies in the c-axis of the $\mathrm{Al}_{5} \mathrm{Fe}_{2}$ phase and inhibits the growth of alloy layer. This conclusion is contradictory to the finding of Springer et. al. in Ref. [10]. This distinction could be caused by the different initial status of the materials. In Ref. [10], the test started with no pre-formed IMPs, whereas the $\eta-\mathrm{Al}_{5} \mathrm{Fe}_{2}$ IMP was already formed in Ref. [18].

\section{Target of the Current Work}

Summarizing the state of the art, three important findings are important for this work:

AlSi3Mn1 and AlSi5 filler materials showed improvement on CMT welding [5].

$\mathrm{Si}$ in Al-melt reduces the thickness of the brittle layer in IMP [10]. If an IMP already exists, Si may also inhibit the alloy layer to growth. Both lead to a better ductility of the IMP layer.

Different alloying elements may increase the ductility of $\mathrm{Fe}-\mathrm{Al}$ intermetallic alloy as a bulk material.

Based on these facts, a coating system consisting of $\mathrm{Al}, \mathrm{Si}, \mathrm{Mn}$, etc. should be developed which can be applied on steel substrate in order to obtain a thin ductile intermetallic layer to join steel parts with Aluminum during the casting process. By the formation of this kind of material joining with a ductile layer property, the joining properties between steel and $\mathrm{Al}$ in such hybrid casted part should be improved. The assumption that different alloying elements may influence the IMP growth dynamics in a positive manner, should be used as the fundamental physical starting point of this work.

\section{Experimental Setups}

\subsection{Steel Substrate and Aluminum Alloys}

Because of the awareness in Ref. [18] that the kinetics of diffusion within the coating layers may not be significantly influenced by the steel substrate chemistry of low carbons steels, the following three different steels (Table 1) were selected: an European low carbon deep drawing steel DC04 without any initial coating for the new coating system; a hot rolled complex phase steel CPW 800 with electro galvanized $\mathrm{Zn}$ coating (EG $\mathrm{Zn}$ coating) and a boron steel MBW 1500 (22MnB5) for hot forming (see [16]) with hot dipped Al-Si coating, which is similar to the steels in Refs. [17, 18]. These two steels with industrial coatings should work as reference for the investigations in the new coating system.

For the hybrid casting, an Aluminum alloy, which contains 9-11.5 wt.\% $\mathrm{Si}$ and small amount of $\mathrm{Mg}$ (Table 2), was selected, because of its suitability for pressure die casting in automotive applications.

\subsection{Description of the Coating Systems}

An existing industrialized EG $\mathrm{Zn}$ and a hot dip Al-Si coating were investigated, besides a new PVD coating system based on Al-Si.

Table 1 Chemical composition (wt. \%) and coating layer of three different steels.

\begin{tabular}{lllllllllll}
\hline Steel/ wt.\% & $\mathrm{C}$ & $\mathrm{Si}$ & $\mathrm{Mn}$ & $\mathrm{P}$ & $\mathrm{S}$ & $\mathrm{Al}$ & $\mathrm{Ti}+\mathrm{Nb}$ & $\mathrm{Cr}+\mathrm{Mo}$ & $\mathrm{B}$ & $\mathrm{V}$ \\
\hline DC04 & 0.08 & - & 0.4 & 0.03 & 0.03 & - & - & - & - & - \\
CPW 1000 & 0.2 & 0.8 & 2.2 & 0.08 & 0.15 & 2 & 0.15 & 1.2 & 0.005 & 0.2 \\
MBW 1500 & 0.25 & 0.3 & 1.4 & 0.02 & 0.005 & 0.05 & 0.05 & 0.2 & 0.0035 & - \\
\hline
\end{tabular}

Table 2 Alloying content (wt. \%) of the investigated Aluminum alloy.

\begin{tabular}{llllllll}
\hline AlSi9MgMn & $\mathrm{Si}$ & $\mathrm{Fe}$ & $\mathrm{Cu}$ & $\mathrm{Mn}$ & $\mathrm{Mg}$ & $\mathrm{Zn}$ & $\mathrm{Ti}$ \\
\hline Max & 11.5 & 0.13 & 0.03 & 0.8 & 0.5 & 0.08 & 0.15 \\
$\mathrm{Min}$ & 9.5 & - & - & 0.5 & 0.1 & & 0.04 \\
\hline
\end{tabular}




\subsubsection{EG Zn Coating}

The industrial EG Zn coating layer is shown in Fig. 2a. The $\mathrm{Zn}$ layer is approximately $7 \mu \mathrm{m}$ thick. Between the steel and $\mathrm{Zn}$, a good connection without failures can be identified as expected. There is no material inter-lock or form locking mechanism which can be seen later in Fig. 8 where hybrid castings were carried out. The small pores in the $\mathrm{Zn}$ coating layer are caused by the sample preparation, since the $\mathrm{Zn}$ layer is very soft in comparison to the very hard steel base material, which in this case is a CPW 800 with min. $800 \mathrm{MPa}$ tensile strength.

4.2.2 Industrialized AlSi Coating on a Steel for Hot Forming (MBW 1500)

The surface layer of the hot dipped Al-Si layer is the same as described in Section 2.3. It is approximately $30 \mu \mathrm{m}$ thick and consists of two sub-layers (see Fig. 2b). There are many additional small IMP islands in the second thicker layer as well, which are described in Refs. $[17,18]$.

The first thin sub-layer has a thickness of approximately 5-7 $\mu \mathrm{m}$ and the second thicker layer is about $25 \mu \mathrm{m}$. EDX measurements show that the first thin layer contains 6-8 $\mathrm{wt} \% \mathrm{Si}$. In the second thicker layer, there is a strong segregation of $\mathrm{Si}$, so that their exact content is difficult to determine. In the thinner layer there is also Fe besides Al. In the thicker layer, no Fe could be found.

\subsubsection{PVD Al-Si Coating System on DC04} Uncoated Steel

Here the target is to apply a $20 \mu \mathrm{m}$ Al-Si coating layer with a thinner ductile first layer, which is different from the industrial Al-Si coating in Section 4.2.2. The influence of other elements like Mn, B, etc. should be investigated in later work. A PVD (physical vapor deposition) method was used to make it. The system CC800® from CemeCon equipped with four cathode positions was used which allows very homogeneous coating. During the PVD coating process a high energy process $(7,000 \mathrm{~W}$ and $4 \mathrm{~h})$ was selected in order to accelerate the coating process and shorten the time consumption. Therefore, both the steel substrate and the PVD targets were subjected to enhanced temperature up to $450{ }^{\circ} \mathrm{C}$. At this temperature also diffusion in the layer and between the Al-Si layer and the steel substrate takes place. A pure $\mathrm{Al}$ and an additional $\mathrm{Al}-10 \% \mathrm{Si}$ target were used to obtain the desired chemical composition of the coating layer. The steel substrate is the DC04 steel, which is cleaned and etched with an HCL acid before coating.

The realized PVD coating layer of the Al-Si coating is shown in Fig. 3. It is approximately $20 \mu \mathrm{m}$ thick and the layer consists also of two sub-layers; the first steel contacting layer with the thickness among 1-3 $\mu \mathrm{m}$ and the second layer above of another $15-17 \mu \mathrm{m}$.

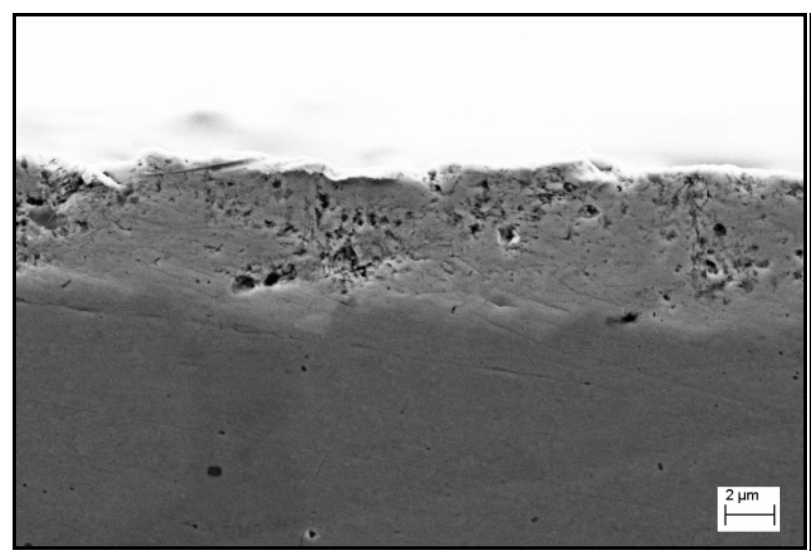

(a)

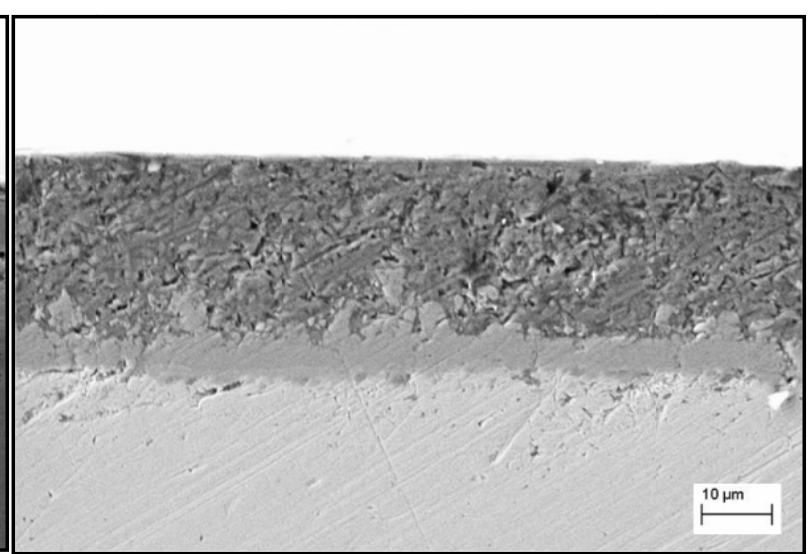

(b)

Fig. 2 (a) Microstructure of an EG Zn coating; (b) An industrial hot dipped Al-Si coating. 


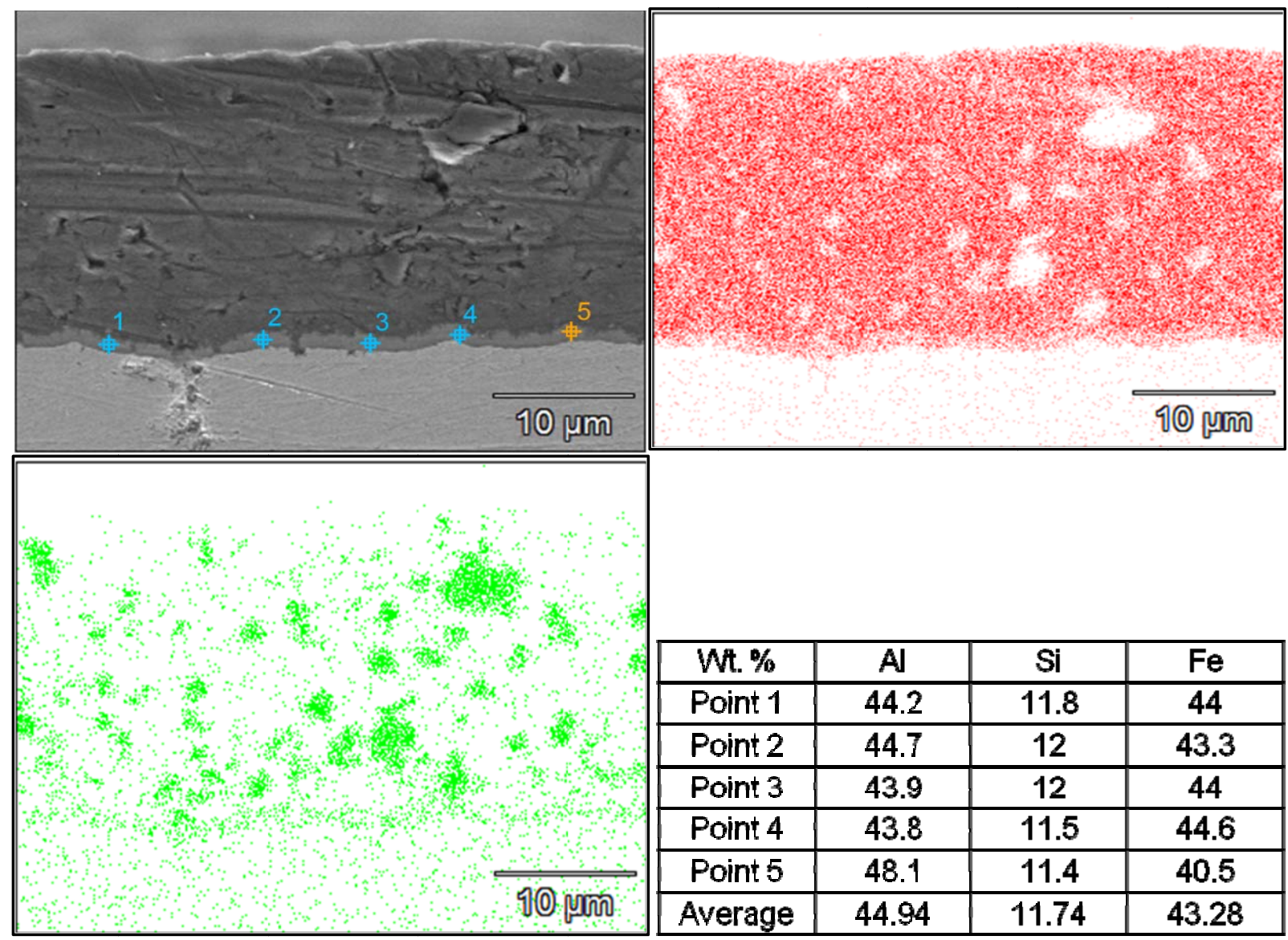

Fig. 3 Distribution of $\mathrm{Al}$ (red) and Si (green) in the coating layer PVD Al-Si on DC04 steel as well as the chemical composition of the first thin layer contacting steel substrate (on 5 points).

SEM EDX (Table in Fig. 3) analysis shows that the first thin $1.5 \mu \mathrm{m}$ layer consists of 40-45 wt.\% Fe, 45 wt.\% $\mathrm{Al}$ and 12 wt.\% Si. The IM-phase of this first layer can thus be approximately written as $\mathrm{Al}_{57} \mathrm{Fe}_{27} \mathrm{Si}_{15}$ and according to the Fe-Al-Si phase diagram [17] it should have a cubic crystal structure of type $\alpha_{2}$ and some orthorhombic $\eta-\mathrm{Fe}_{2} \mathrm{Al}_{5}$. Because of the richness of $\mathrm{Fe}$ and the small thickness (1-3 $\mu \mathrm{m})$ as well as the crystal structure, this layer could be more ductile.

The Si-content in the second thicker layer scatters quite widely in the coating layer, as can be seen in Fig. 3. A kind of alloy segregation process took place obviously during the high energy PVD process. Also a clearly reduced $\mathrm{Al}$-content in the first thin layer and an enrichment of $\mathrm{Si}$ in the direct vicinity of the thin 1-3 $\mu \mathrm{m}$ sub layer can be seen.

\subsection{Sample Shape and High Pressure Die Casting}

A shear tensile sample (in Fig. 4) has been selected to investigate the mechanical properties of the different hybrid casting configurations. For this sample, $10 \mathrm{~mm} \mathrm{Al}$ is casted only on the one face of the $1.5 \mathrm{~mm}$ steel sheet. If there is no material joining between steel and $\mathrm{Al}$, the two parts will separate automatically. In the other case, if these two parts stay together after hybrid casting, a kind of material joining must be there and the shear tensile strength can be determined.

In order to produce the samples above and analyze the different types of coating systems and materials, casting dies were developed for high pressure die casting and casting trials were done (Fig. 5). Both shear tensile samples and pull out samples can be 

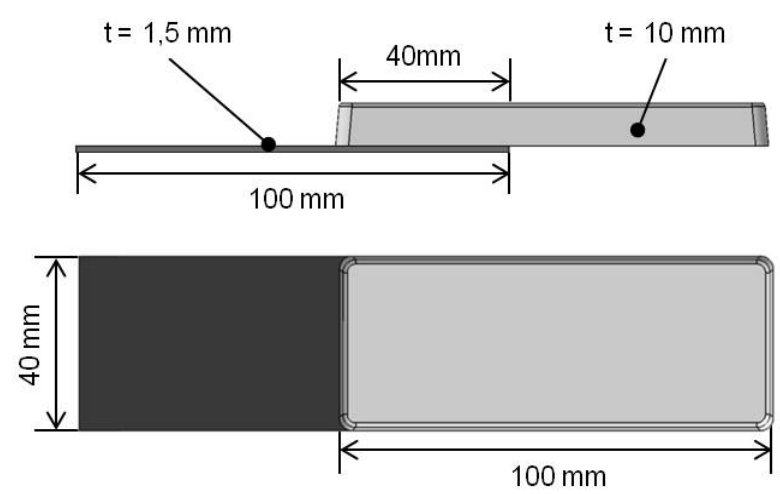

Fig. 4 Sample shape for pure shear tension test.

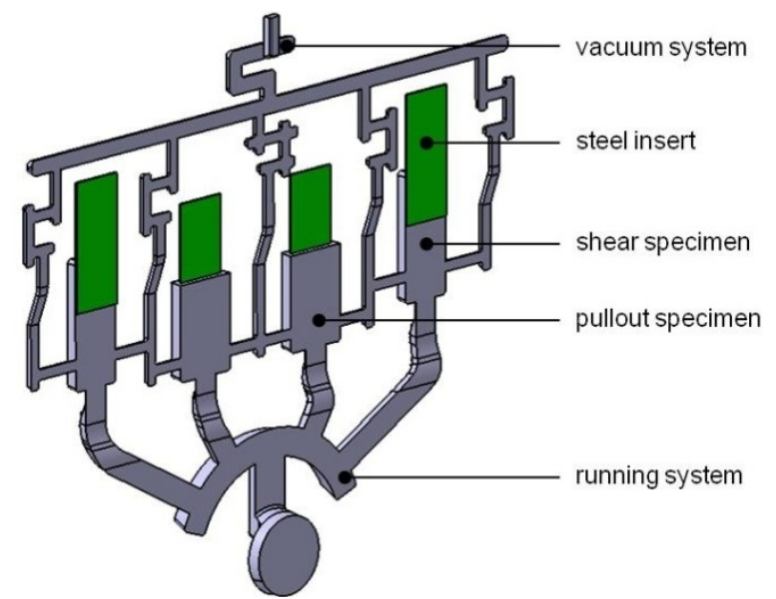

Fig. 5 Injection die for a high pressure die casting trial.

produced in the same step. However, in this work only the results of the shear tensile samples are presented and discussed, since in the pull out samples form, force locking and material connections are present in the same time.

The injection gate size of the die was $50-250 \mathrm{~mm}^{2}$. The injection piston speed was $1.0-3.0 \mathrm{~m} / \mathrm{s}$ at a total die pressure of up to 600 bar. The injection velocity as a product with the section size of the injection gate die is defined as a volume flow rate $\left[\mathrm{mm}^{3} / \mathrm{s}\right][20]$. This flow rate was changed in the range between 3,000 and $8,000 \mathrm{~mm}^{3} / \mathrm{s}$. The Al-melt-temperatures were between 685 and $750{ }^{\circ} \mathrm{C}$. And the coated steel inserts for the hybrid casting tests were at RT or pre-heated to different temperatures between 200 and $300{ }^{\circ} \mathrm{C}$ (see Table 3).

\section{Results and Discussion}

\subsection{Mechanical Behavior}

After acquiring the Steel-Al hybrid casting samples, the shear tensile tests were done by using a Zwick tensile test machine with $10 \mathrm{~mm} / \mathrm{min}$ testing speed, which corresponds to a quasi-static test. The force-displacement curves were generated and the fracture surfaces of the samples were analyzed after the tensile test by SEM.

Extensive trials with different pressure die casting parameters were carried out and the most important influencing parameters on the hybrid casting results concerning tensile shear strength can be found as follows (Table 3).

In Fig. 6 the force-displacement diagrams of the four different coatings are shown. The volume flow rate was found to be very important. Trials with lower volume flow rate lead to much worse results than that with a higher rate more than $7,000 \mathrm{~mm}^{3} / \mathrm{s}$.

\subsubsection{Al-Si Industrial Hot Dipped Coating}

Experimental results show that for all casting conditions investigated in this work, no joint could be determined between $\mathrm{Al}$ and steel with an industrially hot dip coated Al-Si layer (see Section 4.2.2). Therefore no detailed results are presented here.

Table 3 Results of different coating systems at different casting conditions.

\begin{tabular}{llll}
\hline Coating type & Temperature of Al-melt $\left[{ }^{\circ} \mathrm{C}\right]$ & Pre-heating Temperature $\left[{ }^{\circ} \mathrm{C}\right]$ & Mean shear strength $[\mathrm{MPa}]$ \\
\hline \multirow{3}{*}{ EG Zn on CPW 800 } & 685 & RT & 14.31 \\
& 750 & RT & 15.18 \\
& & 200 & 18.32 \\
\hline \multirow{2}{*}{ PVD Al-Si on DC04 } & \multirow{2}{*}{685} & RT & 0.2 \\
& \multirow{2}{*}{750} & 300 & 11.3 \\
& & RT & 0 \\
\hline
\end{tabular}




\subsubsection{EG Zn Coating and PVD Coatings}

For the EG $\mathrm{Zn}$ coating, a maximum force between 30 and $35 \mathrm{KN}$ could be measured (Fig. 6a) when using appropriate volume flow rate. The mean value is about $30 \mathrm{KN}$, which corresponds to a tensile shear strength of approximately $18 \mathrm{MPa}$. Here, the shape of the F-S-curves is quite independent from the pre-heating conditions of the steel inlays. The scatters of the curves are quite large. After the maximum force was reached, the F-S-curves drop immediately to zero, which indicates that the rupture must be brittle.

The mean value of the critical shear stress $(6$ samples) using $750{ }^{\circ} \mathrm{C} \mathrm{Al}$ melt temperature is 15.18 $\mathrm{MPa}$, which is slightly higher than that using $685^{\circ} \mathrm{C}$ Al melt temperature(14.31 MPa). The influence of the pre-heating of the steel inserts is much higher than the temperature of $\mathrm{Al}$ melt. At $750{ }^{\circ} \mathrm{C}$ Al melt temperature and with $200{ }^{\circ} \mathrm{C}$ pre-heated steel, the shear strength rises to $18.32 \mathrm{MPa}$.

It can be concluded, that the pre-heating of the $\mathrm{Zn}$ coated steel part before casting with $\mathrm{Al}$ is very important for the joining strength. Moreover, the consistency of the shear strength has also been highly improved when the steel sheet is pre-heated.

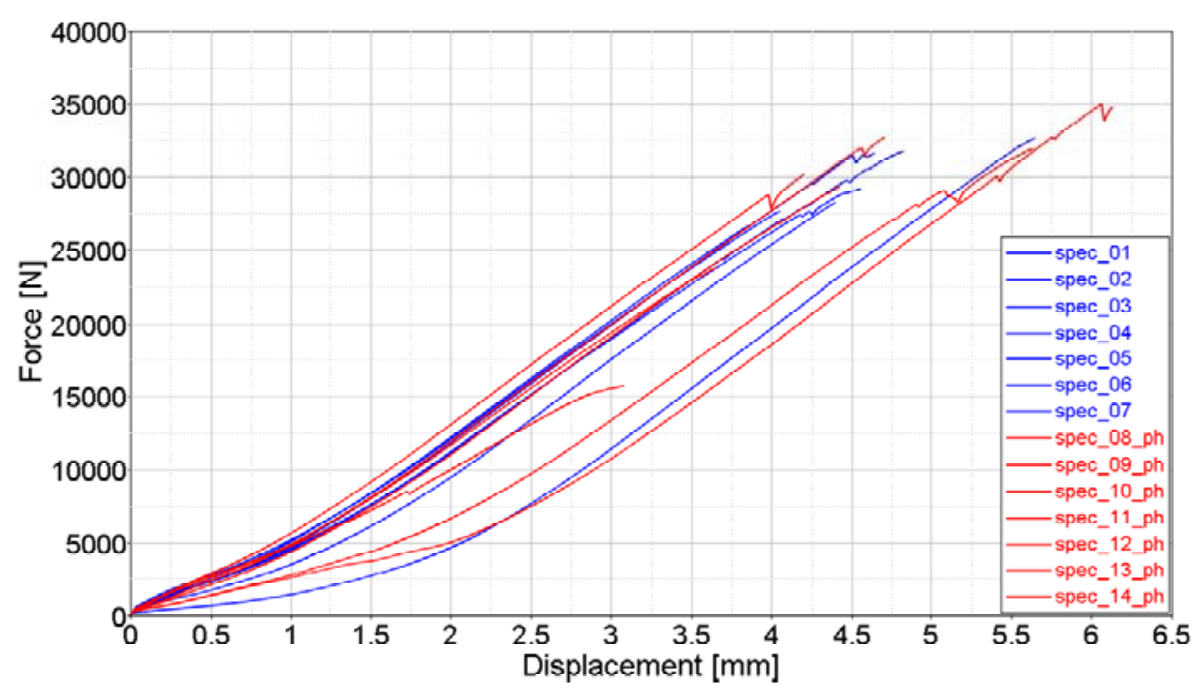

(a)

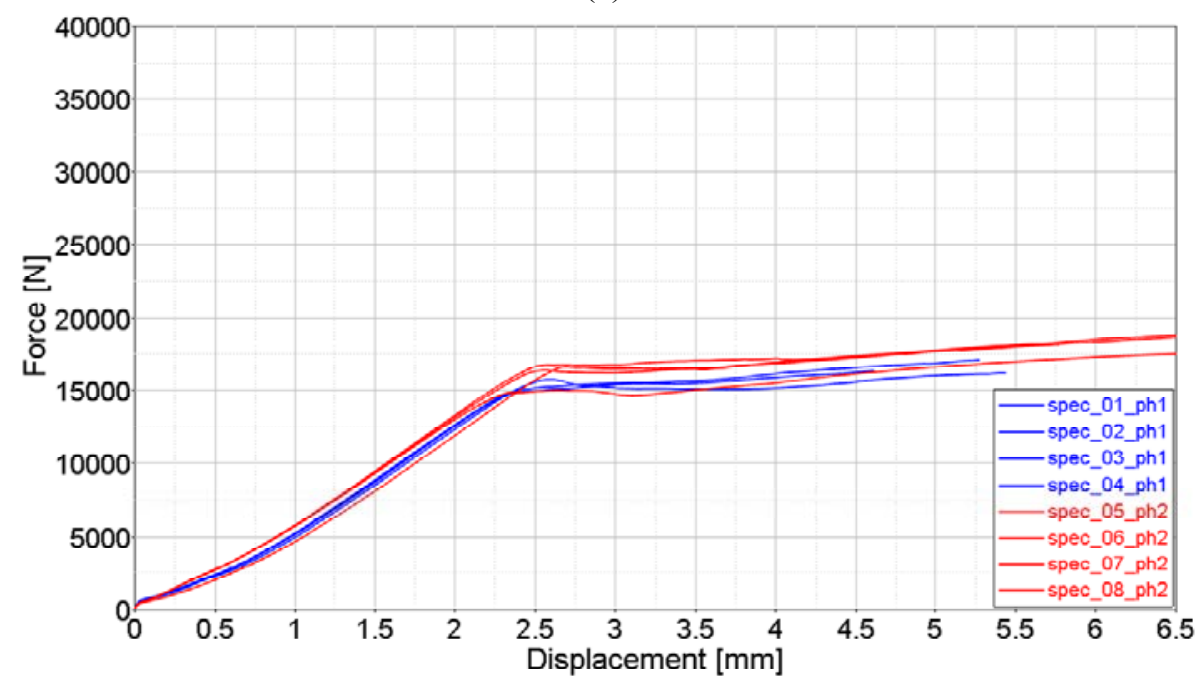

(b)

Fig. 6 (a) Shear force and displacement curve of a Zn coated steel (with (red) and without pre heating (blue) ) hybrid casted by a $\mathrm{Al}$ at $750{ }^{\circ} \mathrm{C}$; (b) A PVD Al-Si coated steel with pre heating at $220^{\circ} \mathrm{C}$ (blue) and $300{ }^{\circ} \mathrm{C}$ (red) when casted by a Al-melt at $685^{\circ} \mathrm{C}$. 


\subsubsection{PVD Al-Si Coating on Bare Steel DC04}

For the steel sheet coated by a PVD Al-Si layer, the results are totally different. At first, the Al melt temperature in this case is much more important than in case of EG Zn coated steel (see Table 3). For this coating, no joints could be realized if the $\mathrm{Al}$ melt is heated to $750{ }^{\circ} \mathrm{C}$. The pre-heating of the steel sheet is also very important. Without pre-heating no joint could be made at any $\mathrm{Al}$ melt temperature. A very stable joint, which has a more than $10 \mathrm{MPa}$ high tensile shear strength and very small scatter (Fig. 6b), could be determined when the steel sheet is heated to 220-300 ${ }^{\circ} \mathrm{C}$ before casting at a $\mathrm{Al}$ melt with a temperature of $685^{\circ} \mathrm{C}$.

In the force-displacement diagrams (Fig. 6b), one can see very consistent results. The statistical analysis confirms the first visual impression. For the two test series the standard deviation for the first series (blue, $\mathrm{T}_{\text {preheating }}=220^{\circ} \mathrm{C}$ ) was $0.87 \mathrm{MPa}$ at a mean shear strength value of $9.9 \mathrm{MPa}$. For the second series test (red, $\mathrm{T}_{\text {preheating }}=300^{\circ} \mathrm{C}$ ) it was $0.44 \mathrm{MPa}$ at a shear strength value of $11.3 \mathrm{MPa}$. For each trial 8 samples were tested.

In comparison to the EG $\mathrm{Zn}$ coating, these F-S-curves show not only a linear elastic part, but also a continues deformation of the sample at nearly constant force level with the increasing displacement, which indicates a stable growth of already initiated cracks between $\mathrm{Al}$ and steel at the joining area.

\subsection{Fracture Mode and Analysis}

From the description above, one can see that the shear strength of the $\mathrm{Zn}$ coated steel (EG) is almost $100 \%$ higher than the PVD Al-Si coated steel (Fig. 6). However, the force displacement curves behave totally differently. In order to understand the differences, the fracture surface of the shear tensile test specimen was analyzed below.

\subsubsection{EG Zn Coated Steel}

From the macro picture (Fig. 7a) one can see that part of the Al cast was stuck on the steel sheet surface.
And the fracture surface of this rough area A is shown in Fig. 7b. The flat area indicated by B (Fig. 7c) show a smooth fracture. The area of this brittle zone B is much larger than that of the ductile zone A.

Due to the adhesion of Al cast on the steel sheet and a ductile fracture in the rough area $\mathrm{A}$, the shear force of EG Zn coated steel sheet is very high. In Fig. $7 \mathrm{~b}$ the fracture surface in the area A of Fig. 7a looks like a honeycomb structure, which usually can be interpreted as a ductile fracture. When the chemical composition of different zones in this area $\mathrm{A}$ is measured by EDX, a mixture of $\mathrm{Al}$ und $\mathrm{Si}$ (varies from $\mathrm{Al}$ : 75-95 wt. \%, Si: $1.5-19$ wt. \%) can be found. The fracture occurs obviously in the Al-cast because of the existence of $\mathrm{Al}$ and $\mathrm{Si}$ the Al-cast alloy. The fluctuation of the chemical composition might be the result of alloy segregation during the solidification process of the $\mathrm{Al}$ alloy. A kind of smaller craters is visible in the middle of the picture of Fig. $7 \mathrm{~b}$. There, the Si content is roughly $17 \%$. At the flat areas in the left corner, the $\mathrm{Si}$ content is only $1-2 \%$. Since Si reduces the ductility of Al base material, the fracture in the middle is less ductile, whereas the areas on the corner could be interpreted as a sliding surface of the highly deformable almost pure $\mathrm{Al}$ grains.

However, since the ductile area A is very small, once a critical force is reached (see Fig. 6a), the steel-Aluminum joining breaks suddenly and the force drops to zero without generating any plastic deformation in the major joining areas. This can be explained by the brittle facture surface shown in Fig. $7 \mathrm{c}$ and $7 \mathrm{~d}$, which correspond to the dominating area $\mathrm{B}$ of the sample (Fig. 7a).

It is interesting that $\mathrm{Fe}$ has been detected in the fracture surface besides $\mathrm{Al}$ and $\mathrm{Si}$ through $\mathrm{EDX}$ analysis (Fig. 7c). In the points 1, 3, 6, 9 when the EDX beam was focused on the bottom of the crater, more Fe could be detected. In other case, at points 2, $5,7,8$, when EDX beams were focused on the flat top area of the fracture surface, no Fe could be found.

The reason for the difference of Fe content can be 


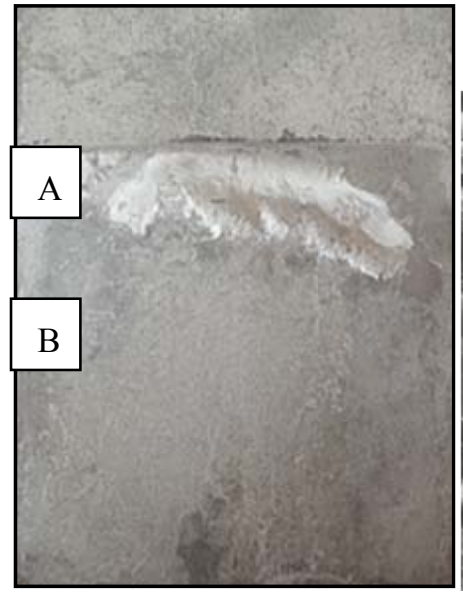

(a)

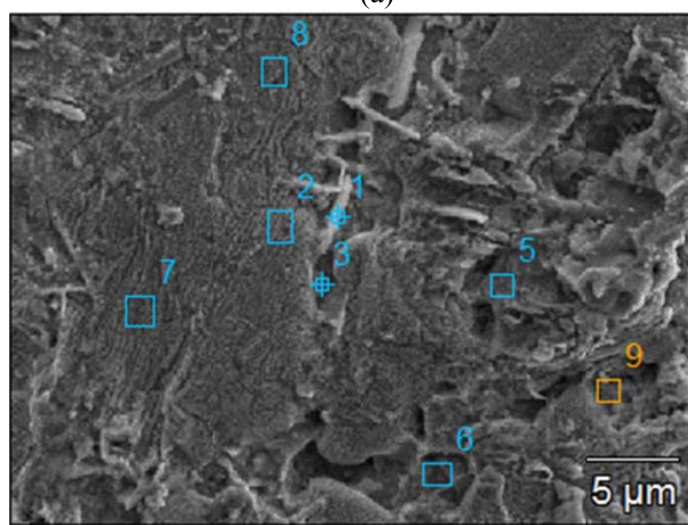

(c) Area B

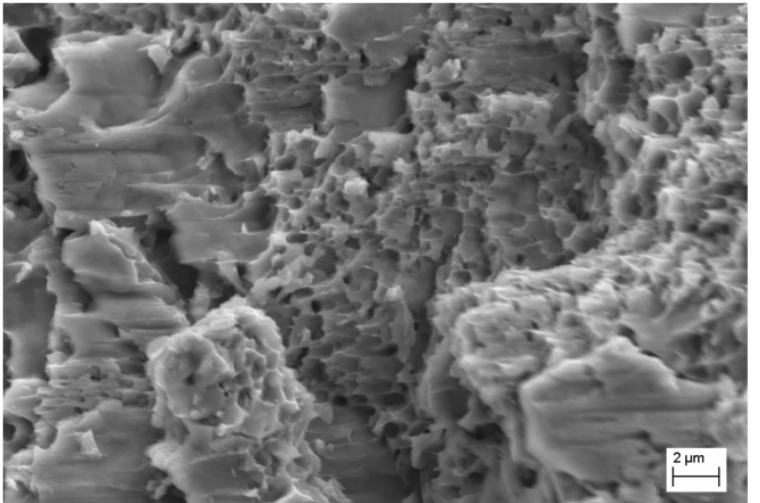

(b) Area A

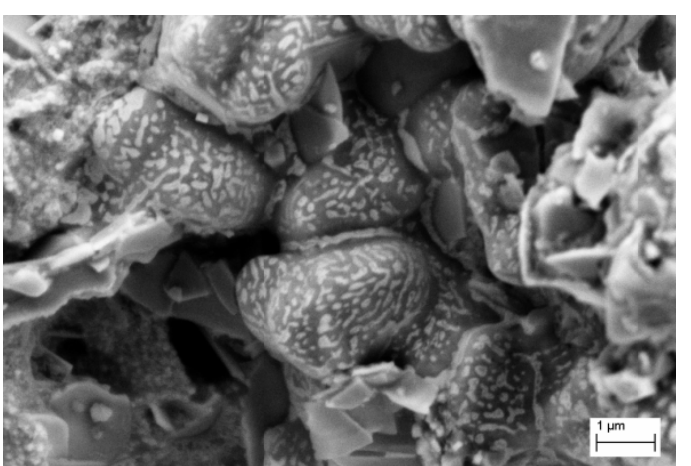

(d)

Fig. 7 (a) Shear tensile fracture surface of Zn coated steel sheet; (b) rough area A; (c) flat area B and EDX measuring area; (d) enlarged area in flat area B (“asian script” zone: light spots: high Zn content approximately 60-70 wt. \%, Rest: Al; dark: lower content of Zn of approximately 50 wt. \%, Rest Al.

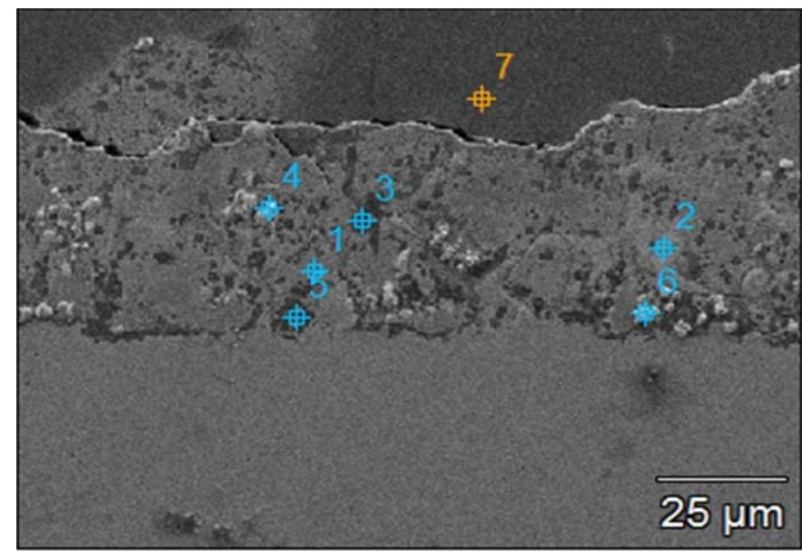

(a)

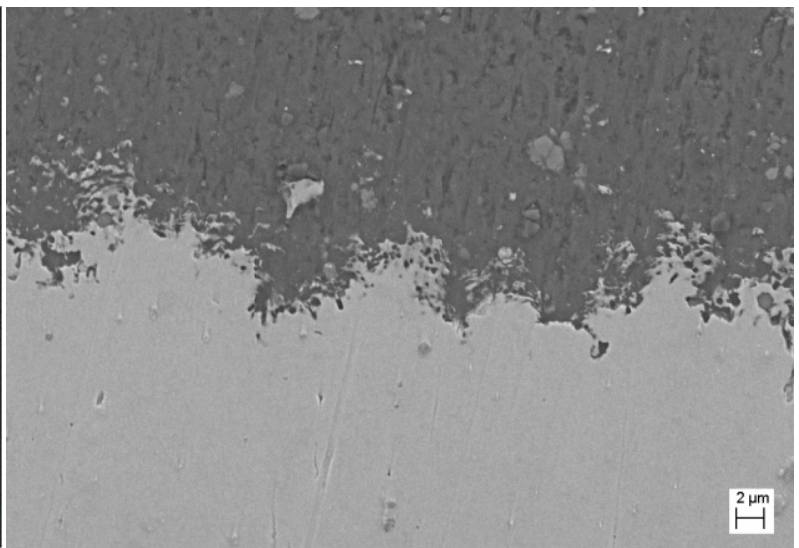

(b)

Fig. 8 (a) Cross section of Zn coated steel sheet after hybrid casting; (b) area with a kind of microscopic interlock of materials between $\mathrm{Al}$ and Steel surface (Steel: light, $\mathrm{Al}$ : dark)

found when we observe the cross section of the hybrid casted samples, which is shown in Fig. 8. It shows two typical areas of cross section between steel and Al. The kind of area in Fig. 8a can normally be found at the corner or edge and the type of area in Fig. 8b is more in the middle of the sample. In Fig. 8a, a mixed layer consisting of $\mathrm{Al}$ and $\mathrm{Zn}$ has been formed. Also some micro cracks can be seen in the layer. This area 
may correspond to the fracture in region B (see Figs. $7 \mathrm{c}$ and $7 \mathrm{~d})$.

In the area of Fig. $8 \mathrm{~b}$ one can see many microscopics interlocking of materials between the dark Al-cast alloy on the top and the steel on the bottom. Through this microscopic interlocking, $\mathrm{Al}$ and steel form an additional joining besides the material connection. When this connection is very strong, the sample could even break in the area of Al-cast, as can be seen in Figs. 7a and 7b. If the connection is weaker, the fracture may go through these form locking connections. During this fracture process, Al particles can be pulled out of steel, so that at the bottom of the fracture surface, $\mathrm{Fe}$ can be detected besides $\mathrm{Al}$ and $\mathrm{Si}$ (see points 1, 3, 6, 9 in Fig. 7c). So area B could be also generated in these weak areas.

In addition, further EDX analysis on cross section of the shear tensile sample shows that Al diffuses slightly into the $\mathrm{Fe}$ metal and forms a material mixture consisting of $47 \% \mathrm{Al}, 7 \% \mathrm{Si}, 22 \% \mathrm{Fe}$ and $25 \% \mathrm{Zn}$ (see Box 8 in Fig. 9). An element analysis by EDX mapping method shows clearly this kind of material mixture on the corner of the same sample. The diffusion depth of $\mathrm{Al}$ into the $\mathrm{Fe}$ is less than 3-4 $\mu \mathrm{m}$, since in Box 9 no $\mathrm{Al}$ can be detected (Fig. 9). Fe could be detected up to $3 \mu \mathrm{m}$ from the steel surface in Box 8 , but not further. Above Box 8, a mixture of $\mathrm{Al}, \mathrm{Si}$ and $\mathrm{Zn}$ can be found. This kind of material mixture of Fe-Al-Zn-Si enables a type of material based on connection between $\mathrm{Al}$ and steel during the hybrid casting. Therefore, the craters in Fig. 7c could be formed during the shear tensile test when $\mathrm{Al}$ materials were pulled out of the interface layer between $\mathrm{Al}$ and steel.

In the flat area $\mathrm{B}$ of this fracture surface one can also see a kind of "Asian script" structure (Fig. 7d). The chemical content of these "Asian script" zones could also be determined by EDX analysis. The light spots show higher $\mathrm{Zn}$ content with approximately 60-70 wt.\% $\mathrm{Zn}$ and 30-40 wt.\% Al; the dark spots, on the contrary, show lower content of $\mathrm{Zn}$ of approximately $50 \mathrm{wt} . \%$ and $\mathrm{Al} 50 \mathrm{wt}$ \%. The fracture surface is very smooth. This fracture may correspond to the Al-Zn mixed zones in Fig. 8a, where $\mathrm{Zn}$ and $\mathrm{Al}$ contents can be found as well.

So, based on the findings in Figs. 7-9, it can be concluded, that the observations up to now $[5,10,12]$, that $\mathrm{Zn}$ may help the joining of $\mathrm{Al}$ and steel, can be explained by the following way:

1st: There is a material based connection between steel and $\mathrm{Al}$, which consists of an $\mathrm{Al}$ rich $\mathrm{Al}-\mathrm{Fe}$ layer with almost in average $25 \mathrm{wt} . \% \mathrm{Zn}$ and additional 7 wt.\% Si. The local $\mathrm{Zn}$ content can be up to $70 \mathrm{wt} \%$ and thus comparable to Ref. [11].

2nd: The connection is also based on the microscopic material interlock between $\mathrm{Al}$ and Steel, which is enabled by the Zn-coating. Thus, it is a form locking connection as well.

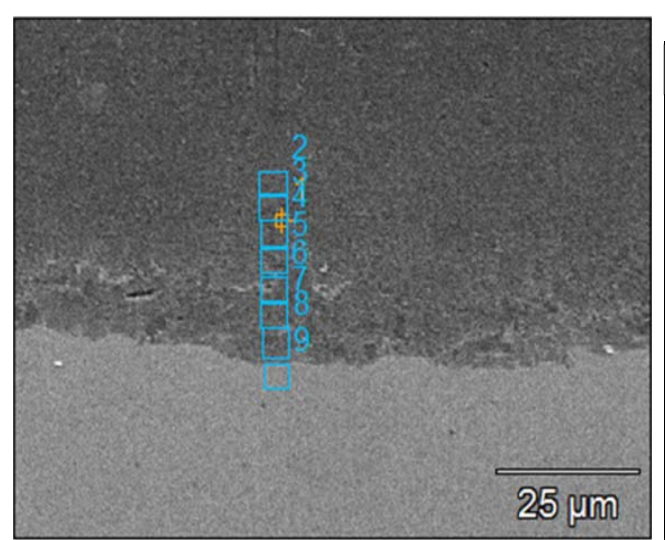

(a)

\begin{tabular}{|c|c|c|c|c|}
\hline 8ox/wl.\% & Al & Si & Fe & Zn \\
\hline 1 & 63.54 & 18.85 & 0 & 17.61 \\
\hline 2 & 73.07 & 8.32 & 0 & 18.61 \\
\hline 3 & 65.86 & 16.66 & 0 & 17.48 \\
\hline 4 & 59.07 & 17.02 & 0 & 23.91 \\
\hline 5 & 54.87 & 17.4 & 0 & 27.73 \\
\hline 6 & 68.67 & 7.23 & 0 & 24.1 \\
\hline 7 & 57.31 & 8.62 & 0 & 34.07 \\
\hline 8 & 46.73 & 6.58 & 22.12 & 24.57 \\
\hline 9 & 0 & 0.72 & 99.28 & 0 \\
\hline
\end{tabular}

Fig. 9 (a) Cross section of $\mathrm{Zn}$ coated steel sheet after hybrid casting and the (b) chemical composition of the Al-Fe-Zn mixture in the first 3-4 $\mu \mathrm{m}$ from steel surface: Box 8 consisting of 47 wt.\% Al, 6.6 wt.\% Si, 22 wt.\% Fe and 25 wt.\% Zn. 


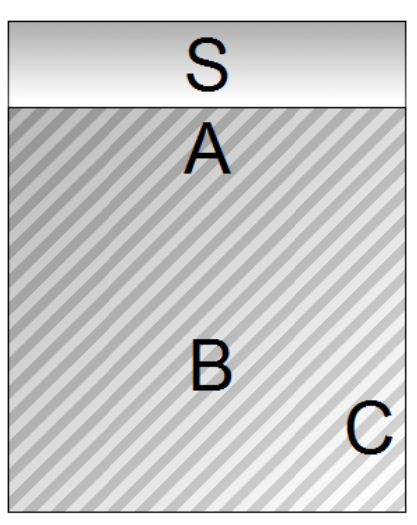

(a)

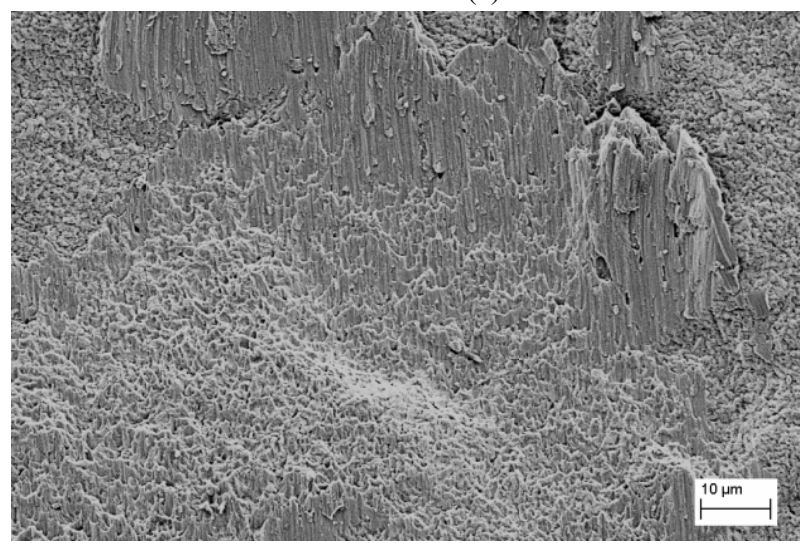

(c)

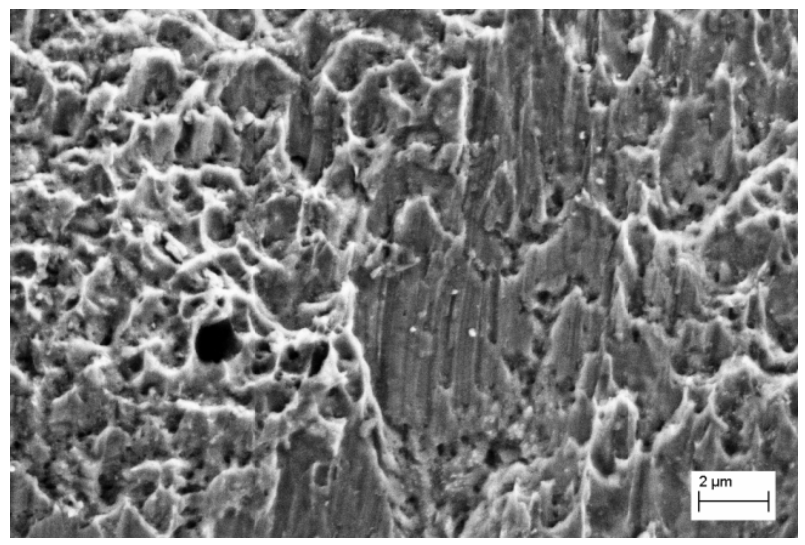

(b)

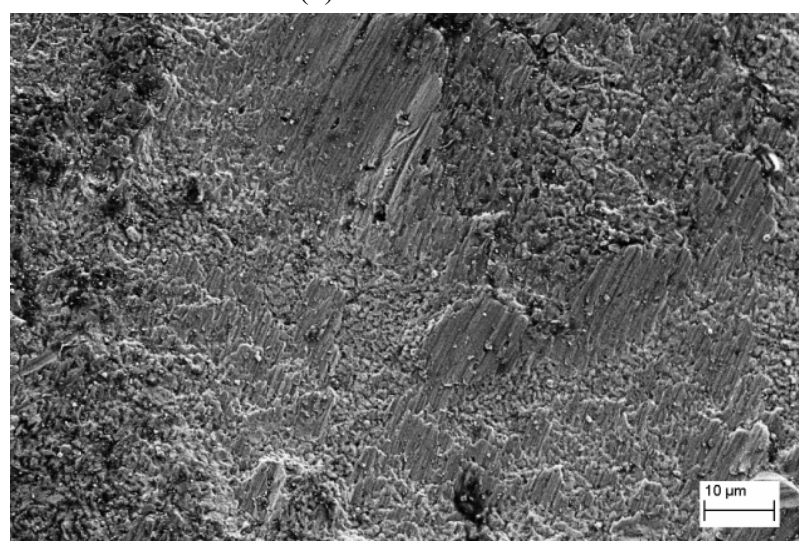

(d)

Fig. 10 (a) Schematic fracture surface of PVD AISi coated steel sheet; (b) SEM area A; (c) SEM area B; (d) SEM area C.

Although EG Zn coating may sometimes enable a joining between $\mathrm{Al}$ and steel, this type of joints is instable and its strength value may vary in a large range [20].

\subsubsection{PVD Al-Si Coated Steel}

The fracture surface of the PVD Al-Si coated steel after hybrid casting process is shown in Fig. 10. Although there is no $\mathrm{Al}$ cast adhesion the steel surface and the shear force of this combination is lower than that of the EG Zn coated steel, the fracture surface looks constantly ductile. In all areas shown in Figs. $10 \mathrm{~b}$ and $10 \mathrm{c}$, one can see a honeycomb like structures everywhere, although the fracture surface in zones A, $\mathrm{B}$ and $\mathrm{C}$ is slightly different. Therefore, the PVD coated steel shows much more ductile fracture surface areas than EG Zn coated steel.

This kind of ductile fracture may explain the constant force level in the force-displacement curve of the PVD AlSI coated steel in Fig. 6b. After reaching a certain critical force, the steel-Al joining and their interface layer start to deform plastically and the shear force remains nearly constant during a period of time or displacement, which is enabled by the plastic deformation through the separation of Al materials.

This assumption could be verified by video screenshots during the shear tensile test. In the beginning, the Al-cast material and steel separate from each other at the upper edge of the tensile shear sample (transition from steel part to Al-steel part). This small crack propagates through the interface steel-Al as the shear tensile test continues with a constant force. The crack never propagates suddenly. This means, that the propagation of the initial failure or crack is stable and the connection between steel and $\mathrm{Al}$ is ductile.

SEM EDX analysis was carried out for this material as well. Firstly, the PVD Al-Si coated surface after the hybrid casting was investigated. This surface has no 
contact to Al melt ((a) (b) Fig. 11a). It shows a microscopically porous surface. This not only enlarges the contact surface between steel and Al-melt, which may improve the reaction, but also lead to the formation of some form lockings between steel and Al cast alloy.

In Fig. 11b, the EDX analysis shows that the surface consists of 1-3 wt.\% $\mathrm{Si}$ and the rest is $\mathrm{Al}$. Because the Al melt contains 9-11 wt.\% Si, this fracture surface must be between Al-Si coating and steel substrate. Thus, the crack runs through the PVD Al-Si coating layer between Al-cast alloy and steel. Due to the strong segregation of Si (see Fig. 3 and Section 4.2.3), there are many areas with strongly reduced Si content and thus lower strength. The same results could also be found on different other PVD Al-Si samples and the results are thus repeatable.

The finding above can be confirmed by the investigations of the cross section in Fig. 12. There, one can see that the crack go through a layer among 16-18 $\mu \mathrm{m}$ from the steel surface. Since the PVD coating layer Al-Si has a total thickness of more than $20 \mathrm{um}$, the material separation or crack goes through the original PVD Al-Si coating layer.

In Fig. 12, one can also observe that the former two layer structures of the Al-Si-coating layer disappear. A similar microscopic material inter locking between Al-Si coating layer and steel surface as in Fig. 8 in

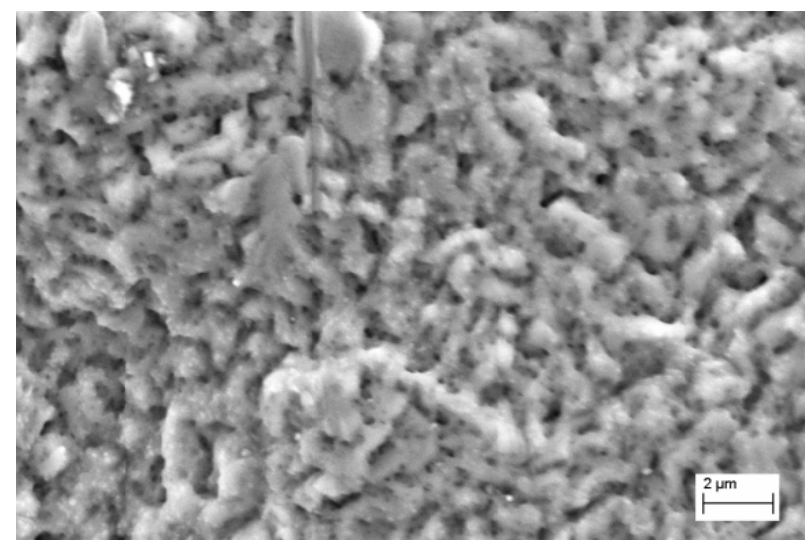

(a) case of $\mathrm{Zn}$-coated steel can be found. So, in addition to the material connection between Fe and Al-Si layer, which is realized by the first $1.5-3 \mu \mathrm{m}$ thick material mixture between Fe, Al and Si (see Fig. 3), a shape and force locking connection has also been formed after the hybrid casting. This is similar to $\mathrm{Zn}$ coated steel and Al. However, the difference between the new PVD Al-Si coating and the known $\mathrm{Zn}$ coating is that only a very brittle material connection could be formed with $\mathrm{Zn}$ coating, whereas with this Al-Si coating, a ductile material connection could be formed.

\section{Comparison to State of the Art and Conclusions}

The alloying elements of the new PVD coating and the hybrid casting process conditions differ from the state of the art in many ways, so that different results could be observed in this work.

At first, the casting alloy used here is different from that in Refs. [7, 8]. Instead of Al-alloy with $0.2 \mathrm{wt} . \%$ $\mathrm{Si}, 0.5$ wt.\% $\mathrm{Mn}$ and 5 wt.\% $\mathrm{Mg}$, an AlSi9MgMn alloy (Table 2) has been used in this work. For this alloy a very good ductile joining between steel and Al could be achieved with the help of the newly developed PVD Al-Si coating. In Ref. [8], using the AlSi5\% and AlSi3Mn1 type of filler material may improve the welding results. However, in both cases,

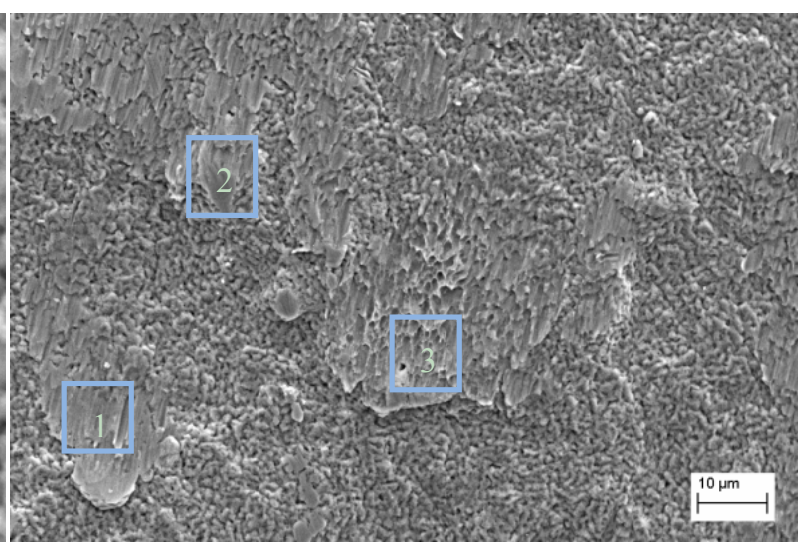

(b)

Fig. 11 (a) Surface of PVD Al-Si coated steel sheet after hybrid casting in Zone S of Fig. 10a. (b) Surface of PVD AISi coated steel sheet after hybrid casting in Zone A of Fig. 10a. Box 1: Al: 99.1\%, Si: 0.9\%; Box2: Al: 99\%, Si: 1\%; Box 3: Al: 96.3\%, Si: $3.7 \%$. 


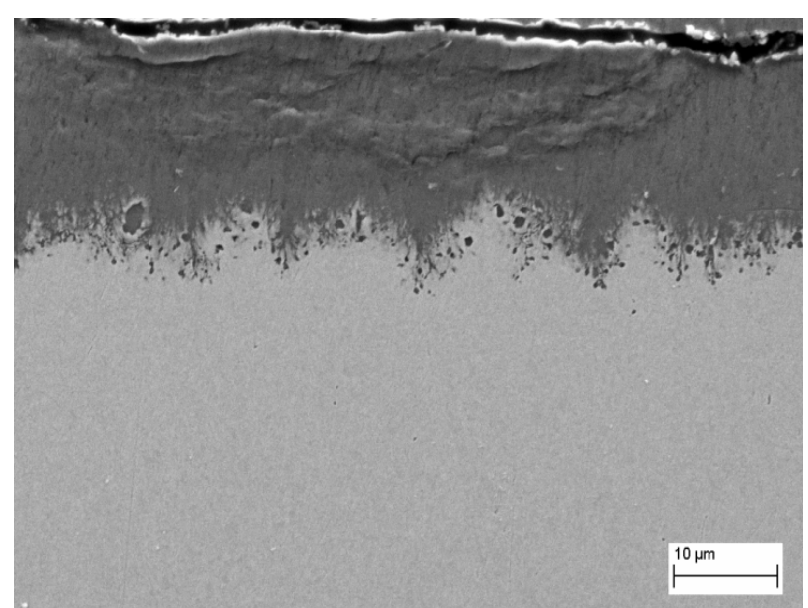

Fig.12 Cross section of a shear tensile sample hybrid casted using the PVD Al-Si coating.

the joining failed not in a ductile way. The alloy contents in these AlSi(Mn)-filler materials are different from the current developed Al-Si coating (see Section 4.2.3), which contents Fe, Al and Si.

As mentioned in Sections 2.2 and 2.3, the investigation in Refs. [10, 12, 17, 18] starts with different initial conditions of materials. In Refs. [10, 12], diffusion experiments were carried out by using bare or $\mathrm{Zn}$ coated steel, whereas in Refs. [17, 18], the diffusion test on IMP-layer growth was done by using industrially AlSi (Si: 7-11 wt. \%) pre-coated steel.

In Refs. [10, 12] it was determined that $\mathrm{Si}$ decelerates the growth of MIP layer in a solid-liquid reaction and accelerates the IMP growth in a further heat treatment in a solid to solid inter-diffusion process. However, for industrially AlSi pre-coated steel [17, 18], Si in Al-alloy always hinders the growth of IMP layer in solid state. The layer ductility may be positively influenced. Obviously, the pre-coating has an influence on the diffusion kinetics. These results can be considered as confirmed by the results of this work, where also a PVD Al-Si coated steel was investigated, since the IMP layer does not grow during the hybrid casting process.

When comparing the hybrid casting process and the metallurgical inter-diffusion tests, it can be concluded, that the diffusion time used in Refs. $[10,12]$ is too long. Therefore the microscopic structures found there may not be valid for this work and further TEM investigations should be done in next step.

Another difference between Ref. [12] and Ref. [18] is about the formation of Kirkendall porosities. In Ref. [12] no voids were found in the Al-Si 5 wt.\% alloy, whereas in Ref. [18] almost 1.5 vol. \% of voids could be found in the industrialized AlSi coating layers with 7-11 wt.\% Si. The last finding is closer to the results of this work, in which small voids or cracks formed within the IMP layers. Counter measures must be developed in the future works to reduce or even prevent the formation of voids, which reduces the layer strength.

For all kind of coatings, the injection volume flow rate of more than $7,000 \mathrm{~mm}^{3} / \mathrm{s}$ is highly important. All trials with lower volume flow rate lead to much worse results. The post casting pressure and die closing time show no influence on the results. The higher volume flow rate results in a shorter die filling time and thus a reduced reaction time between steel and Al-cast alloy. This result is in accordance with the results in Table 3 that a lower Al-melt temperature of $685^{\circ} \mathrm{C}$ enables a better material connection to steel. Lower Al-melt temperature and reduced filling time both result in a restricted diffusion between the PVD Al-Si-layer and steel. So, in order to obtain a ductile material joining, the diffusion must take place, but be restricted in a certain range. In this way, the chemical composition of the first 1-3 um thin layer cannot be drastically changed and remain ductile. In the second thicker 15-20 $\mu \mathrm{m}$ layer, many Si segregations took place, so that zones with high and low Si contents were formed with different material strengths. In the next step, diffusion tests using the conditions above should be carried out to verify this assumption. These facts may be used to explain the material joining mechanism and crack formation (Fig. 13).

$\mathrm{Al}$ and $\mathrm{Si}$ of the Al-Si coating layer diffuse into the steel substrate for about 1-3 $\mu \mathrm{m}$ in depth, which is reinforced by a microscopic material inter-lock between $\mathrm{Al}$ and steel. SEM EDX analysis shows that the 


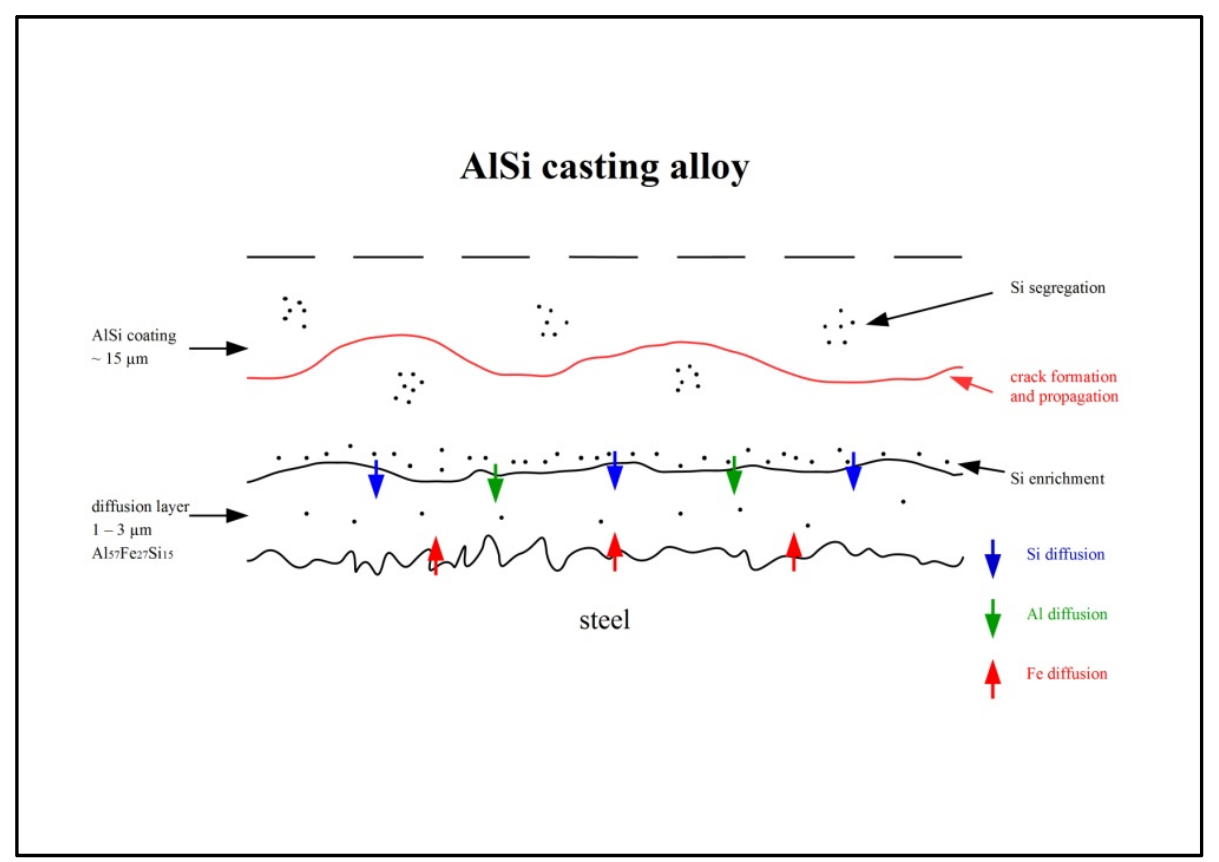

Fig. 13 Principle formation of a Al-Si coating and the crack forming mechanism.

first layer consists of 44 wt.\% Fe, 12 wt.\% Si and 44 wt.\% Al and can be considered as a Fe-rich IM-phase with an ordered cubic $\alpha_{2}$-structure with some additional less ductile rhombic $\eta-\mathrm{Al}_{5} \mathrm{Fe}_{2}$. Because of the crystal structure and the very small thickness of the layer, the ductility and strength is higher. This thin IMP forms an effective ductile material based on joining between Al-Si-layer and steel.

The first layer transits into the second layer with a larger thickness of up to $20 \mu \mathrm{m}$ in depth, which has locally lower strength and very high ductility due to the Si segregation.

During the hybrid casting process, the formation of the material mixture proceeds and the clear separation of the Al-Si PVD layer disappears due to the further diffusion between steel and Al-Si-layer as well as Al-cast alloy. However, the diffusion must be restricted in a certain range, so that the change of the chemical composition of the first thin layer is not too much.

Since the Al-cast alloy contains 9-11 wt.\% Si and some additional $\mathrm{Mn}$ and $\mathrm{Mg}$, its strength is higher than that of the second layer of the Al-Si coating, which has been described in last paragraph. Therefore, this section is the weakest part in the whole steel-Al-cast alloy system and the crack forms and propagates in this layer.

\section{Summary}

In this work, based on different types of steel surface coating, a study on the formation of joining between $\mathrm{Al}$ and steel $(\mathrm{Fe})$ as well as the mechanism of material joining has been carried out.

Although the formation of the Fe-Al-IMP is controlled by their kinetics, which leads to the formation of the brittle IMP with high Al content at the very beginning of the process, before the other IMPs could be formed, the IMP formation may be influenced by alloying elements and pre-coatings.

Originating from the fundamental physical understanding of the formation of Fe-Al intermetallic phases and the influence of different alloying elements such as Mn and Si, a new PVD Al-Si coating, which consists of a very thin 1-3 $\mu \mathrm{m}$ sub layer followed by a thicker 15-20 $\mu \mathrm{m}$ layer, has been developed. The thin layer is chemically quite homogeneous, contains approximately 44 wt.\% Al, 12 wt.\% Si and 44 wt.\% $\mathrm{Fe}$, and can be identified as a 
$\mathrm{Al}_{57} \mathrm{Fe}_{27} \mathrm{Si}_{15}$ intermetallic phase with an $\alpha_{2}$-structure and $\eta-\mathrm{Al}_{5} \mathrm{Fe}_{2}$ structure. This thin layer is formed by inter-diffusion between $\mathrm{Al}$ and $\mathrm{Si}$ on the one side and the steel substrate on the other side and is more ductile. In the thicker 15-20 $\mu$ m layer, only $\mathrm{Al}$ and $\mathrm{Si}$ can be de found and many Si segregations took place, so that zones with high and low $\mathrm{Si}$ contents were formed with different material strengths.

Very encouraging results have been achieved with this surface coating, when Al-alloys with $9-11.5 \% \mathrm{Si}$ in combination with appropriate injection die design and process conditions were used. The Al-melt temperature must be lower than $700{ }^{\circ} \mathrm{C}$ and the volume flow rate must be higher than $7,000 \mathrm{~mm}^{3} / \mathrm{s}$. Both restrict the diffusion process in a certain range. The joints between $\mathrm{Al}$ and steel show a very stable shear tensile force with very low scatter. In addition the shear tensile sample shows a very stable growth of the crack between Al-cast alloy and steel substrate. The fracture surface shows mainly honeycomb like ductile fracture surface. The joining is possible because of the ductile PVD Al-Si layer which enables the material based on joining between steel and Aluminum. The microscopic form locking may contribute further to the joining.

The advantage of this coating layer design is that the hybrid joining can have a ductile behavior. For the very first time, there is a chance to apply this kind of joining on a highly dynamic loaded structure, such as automotive body structure components.

In addition, the mechanism of the material based on joining between Aluminum and $\mathrm{Zn}$ coated steel has been investigated. The material joining is based on a $\mathrm{Fe}-\mathrm{Al}-\mathrm{Si}-\mathrm{Zn}$ material mixture and a microscopic form locking.

In future works additional TEM analysis on crystal structures and diffusion measurements should be carried out.

\section{Acknowledgement}

The author greatly thanks Dr. Gundlach for the valuable discussion in the casting process. He also thanks Mrs. Azim, Mrs. Auf dem Brinken and Mr. Kloska for their technical assistance. This work was founded by the state government of Nordrhein Westfalen, Germany, within the "Ziel 2 program".

\section{References}

[1] Lämmer, H. 1994. Verfahren zum Verbinden zweier Werkstücke aus Metall zu einem Verbundbauteil. German Patent, DE 4414095 A1.

[2] Watkins, T., Erdman, D., Joshi, P., Ludtka, G., Murphy, B., Sabau, A., Yin, H., Zhang, W., Skszek, T., and Niu, X. 2013. "Residual Stress of Bimetallic Joints and Characterization." In Proceedings of the 2013 DOE Vehicle Technologies Annual Merit Review and Peer Evaluation Meeting.

[3] Jochen, D., and Wibbeke, M. 2007. Method for manufacturing of a subframe. German Patent, DE 10 2008020467 A1.

[4] Roeth, T., and Vomhof, R. 2006. Light-weight component. US Patent, US 7152896 B2.

[5] Jacome, L., Weber, S., Leitner, E., Arenholz, E., Bruckner, J., Hackl, H., and Pyzalla, A. 2009. "Influence of Filler Composition on the Microstructure and Mechanical Properties of Steel-Aluminum Joints Produced by Metal Arc Joining." Advanced Engineering Materials 11 (5): 350-8.

[6] Gatzen, M., Radel, T., Thomy, C., and Vollersten, F. 2014. "Wetting Behavior of Eutectic Al-Si Droplets on Zinc Coated Steel Substrates." Journal of Materials Processing Technology 214: 123-31.

[7] Baker, I., and George, E. P. 1998. "The Mechanical Properties of FeAl." MRS Proceedings 552.

[8] Alexander, D. J., Maziasz, P. J., and Wright, J. L. 1998. "Processing and Alloying Effects on Tensile and Impact Properties of FeAl Alloys." Material Science and Engineering A 258 (1-2): 276-84.

[9] Salzar, M., Albiter, A., Rosas, G., and Perez, R. 2003. "Structural and Mechanical Properties of AlFe Intermetallic Alloy with $\mathrm{Li}, \mathrm{Ce}$ and $\mathrm{Ni}$ Additions." Material Science and Engineering A 351: 154-9.

[10] Springer, H., Kostka, A., Payton, E. J., Raabe, D., Kaysser-Pyzalla, A., and Eggeler, G. 2010. "On the Formation Growth of Intermetallic Phases during Interduffsion between Low-carbon Steel and Aluminium Alloys." Acta Materialia 59: 1586-660.

[11] Oberschelp, C. 2012. "Hybride Leichtbaustruktur für den Karosseriebau.” Ph.D. Thesis, RWTH Aachen.

[12] Springer, H., Kostka, A., Santos, F. J., and Raabe, D. 2011. "Influence of Intermetallic Phases and 
Kirkendall-porosity on the Mechanical Properties of Joints between Steel and Aluminum Alloys." Materials Science and Engineering A 528: 4630-42.

[13] Springer, H. 2013-2015. Personal Communications.

[14] Shahverdi, H. R., Ghomashchi, M. R., Shabestari, S., and Hejazi, J. 2002. "Micostructural Analysis of Interfacial Reaction between Molten Aluminum and Solid Iron." Journal of Materials Processing Technology 124: 345-52.

[15] Shih, T., and Tu, S. 2007. "Interaction of Steel with Pure Al, Al-7Si and A356 Alloys." Material Science and Engineering A 454-455: 349-56.

[16] Hein, P., Kefferstein, R., and Dahan, Y. 2006. "New Development in Sheet Metal Forming Technology." In
Proc. Int. Conf.

[17] Suehiro, M., Kusumi, K., Miyakoshi, T., Maki, J., and Ohgami, M. 2003. "Nippon Steel Report No. 88."

[18] Jenner, F., Walter, M. E., Lyenger, R., and Hughes, R. 2010. "Evolution of Phases, Microstructure, and Surface Roughness during Heat Treatment of Aluminized Low Carbon Steel." Metallurgical and Materials Transactions A 41A: 1554-63.

[19] Richards, R. W., Jones, R. D., Clements, P. D., and Clarke, H. 1994. "Metallurgy of Continuous Hot Dip Aluminizing." International Materials Reviews 39 (5): 191-212.

[20] Gundlach, J. 2015. Personal Communications. 